\title{
The Pyrolysis Behavior of Evolved Species from Date Palm Seeds
}

\author{
Mohammed Elamen Babiker ${ }^{1, a}$, A. Rashid A. Aziz², Morgan Heikal ${ }^{3}$, Suzana Yusup ${ }^{4}$ \\ 1,2,3 Centre for Automotive Research and Electric Mobility, Universiti Teknologi PETRONAS, Perak, \\ Malaysia \\ ${ }^{4}$ Green Technology MOR, Universiti Teknologi PETRONAS, Perak, Malaysia
}

\begin{abstract}
The pyrolytic behavior of evolved gases from date palm seeds (DPSs) were measured to gain insight into the mechanism of DPSs pyrolysis. Six different cultivars were used in this study, namely Deglet nour, Piarom, Suffry, Safawi, Mabroom and Aliya. A thermo-gravimetric analyzer (TGA) and a real-time gas analyzer (GA) were used to calculate the mass losses and the mole fraction of evolved gases, respectively. DPSs samples were pyrolyzed in an inert atmosphere condition using argon with a purge rate of $100 \mathrm{~mL} /$ minute. The samples were subjected to non-isothermal operation. An independent single model and parallel reaction model were adopted to interpret the empirical data collected from TGA and GA, respectively. The results reveled that there are three types of pyrolysis zones depending on the main constituents of every cultivars. Moreover, the potentialty of the zones in controlling the pyrolysis behavior was noticeable. The dominant hydrocarbon species in DPSs were $\mathrm{CO}$ and $\mathrm{CH}_{4}$ (40 to $50 \%$ higher than the rest of species). The mole fraction of $\mathrm{CO}$ was 2 to 4 times higher than the mole fraction of $\mathrm{CO}_{2}$. The activation energy and frequency factor of DPSs evolved species showed that Mabroom has the highest activation energy regarding $\mathrm{H}_{2}$ $(63.21 \mathrm{~kJ} / \mathrm{mol})$ and $\mathrm{CO}(74.32 \mathrm{~kJ} / \mathrm{mol})$.
\end{abstract}

\section{Introduction}

In the last four decades, biomass energy became one of the most attractive subject of scientific research as it holds a great potentiality in replacing non-renewable fossil fuel $[1,2,3,4]$. Among the numerous biomass conversion methods, pyrolysis is one of the most popular technologies $[5,6]$. This technology is characterized by its ability to thermally convert the biomass into fuels and chemicals in the absence of oxygen.

Thermo-gravimetric analysis (TGA) is one of the thermal analysis techniques that have been widely used because it provides fast quantitative methods for the investigation of pyrolysis process. Moreover, the technique allow for the evaluation of effective kinetic parameters for different decomposition reactions under isothermal or non-isothermal conditions.

\footnotetext{
${ }^{a}$ Corresponding author : mohammedelamen@gmail.com
} 
The kinetic study of the biomass pyrolysis is necessary to understand the behavior of energy during pyrolysis, gasification or combustion. It also constitutes the preliminary step of combustion and gasification to eliminate the complexity of decomposed constituents and their reactions.

The characteristic parameters such as activation energy, frequency factor, reaction order and reaction model of pyrolysis reactions can be obtained by different mathematical approaches. Reference $[7,8,9]$ and many other researchers, developed mathematical approaches to calculate the kinetic parameters.

On the other hand, macro-scale experiments are identified by complexity and time consuming [10]. Particularly, if the evolved gases are meant to be measured. These types of experiments are not appropriate for kinetics study as the size of samples (20-500 g) are comparatively large. However, it helps in finding some facts about the different behaviors of solid fuel in commercial plants, mainly because of heat and mass transfer restrictions.

Recently, interest in the energy technology of agricultural wastes and crop residues is being considered in many regions of the world. Among these residues and wastes is the date palm seeds, which is one of the promising sources of energy plantation and eco-friendly materials. In this study, the evolved species of the pyrolysis of date palm seeds (DPSs) cultivars were investigated to further comprehend the kinetics behavior of DPSs pyrolysis.

\section{Materials and approaches}

\subsection{Materials}

A specialist importer in dry fruit, namely Syarikat Abdul Ghaffar Trading Sdn.Bhd. in Penang city, Malaysia provided the samples of date palm seeds. Six varieties of DPSs were utilized to prepare the materials of experiments; the samples are categorized into two main types: semi dry and moist. Semi dry type includes Deglet Nour from Tunisia, Piarom from Iran, Suffry and Mabroom from Saudi Arabia and Aliya from Algeria, while moist type include Safawi from Saudi Arabia.

\subsection{Preparations methods}

First, all the samples were prepared by immersing the seeds into a pan of distilled water for 30 minutes in order to soak DPSs. Then, the washing process started by cleansing the seeds thoroughly to remove the remaining parts of flesh and surrounding membranes. The seeds were then left to dry under the direct sunlight until the seeds recovered the original state (dry seeds). After that, the samples were crushed to reduce the volume to the smallest sizes possible before grinding. The common hometype chopper (model-Maxiblend Chopper BL111) was used to grind the seeds, in which the outcome was nearly fine powder. Two sizes of mesh was used, namely No. 60, $250 \mu \mathrm{m}$ and No. $45,355 \mu \mathrm{m}$.

\subsection{Thermogravemtric analysis}

TGA experiments were carried out in an argon environment with a purge flow rate of $100 \mathrm{~L} / \mathrm{min}$. At the start of every experiment, $0.6 \mathrm{~g}$ of the DPSs sample was loaded into a TGA pan. All samples were heated up to $110 \circ \mathrm{C}$ over $10 \mathrm{~min}$ and were maintained at $110{ }^{\circ} \mathrm{C}$ for $30 \mathrm{~min}$ to dehydrate. After the dehydration process, the samples were heated to $900 \circ \mathrm{C}$ for pyrolysis. Concurrently, the compositions of evolved gaseous were measured during the DPSs pyrolysis. A real-time gas analyzer was used to measure a four main components, namely $\mathrm{H}_{2}, \mathrm{CO}_{2}, \mathrm{CO}$ and $\mathrm{CH}_{4}$. Moreover, gas chromatography (GC) analyses were carried out using a micro-gas chromatography (Agilent-C 3800A).

\subsection{Kinetics characteristics of the evolved species:}

To calculate the evolutions of gases species during the pyrolysis of DPSs particles, the process of thermochemical conversion can be represented as independent and parallel reactions as follows:

$$
\frac{d m i}{d t}=k i\left(m i^{*}-m i\right)
$$


Where $m i$ represents accumulated yield of evolved species $i$ at time $t$ and $m i^{*}$ is the ultimate yield of species i (i.e., at $t \rightarrow \infty$ ). The rate constant $k i$ is defined as:

$$
k i=A i \exp \left(-\frac{E i}{R T}\right)
$$

Where $\mathrm{Ai}$ is the pre-exponential factor and Ei is the activation energy for the independent reaction of species i. the relations between the accumulated yields of the evolved gases and the total mass of particles can be stated as follow:

$$
m p 0-m p=\sum_{i=1} m i \quad \text { and } \quad m p o-m p f=\sum_{i=1} m i^{*}
$$

With $\beta=d T / d t$ (where $\mathrm{T}$ is temperature), Eq. (1) can be converted into the following form:

$$
\frac{d m i}{d T}=k i \frac{\left(m i^{*}-m i\right)}{\beta}
$$

Assuming that there is a temperature $T_{\text {peak }}$ which satisfies $\left.\mathrm{d}^{2} \mathrm{mi} / \mathrm{dT}^{2}\right] \mathrm{T}=\mathrm{T}$ peak $=0$, Eq. 5 can be rearranged to the following equation:

$$
-\frac{k i}{\beta} \frac{d m i}{d T}\left|T=T_{\text {peak }}+\frac{m i^{*}-m i}{\beta} \frac{d k i}{d T}\right| T=T_{\text {peak }}=0
$$

In Eq. 2, the differentiation of both sides of the equation with respect to temperature gives the following equation:

$$
\frac{d k i}{d T}=\frac{A_{i} E i}{R T^{2}} \exp \left(-\frac{E i}{R T}\right)
$$

Substituting Eq. 4 and Eq. 7 into Eq. 6, the following equation is finally obtained:

$$
\ln \frac{\beta}{T_{\text {peak }^{2}}}=\ln \frac{A i R}{E i}-\frac{E i}{R T_{\text {peak }}}
$$

In Eq. 8, the kinetic parameters, i.e. activation energy and pre-exponential factor of evolved species during the pyrolysis of DPSs particles were determined from the slope of $\ln \beta / T_{\text {peak }}{ }^{2}$ vs. $1 / T_{\text {peak }}$ as well as the intercept of the fitted plot with respect to $\ln \beta / T_{\text {peak }}{ }^{2}$.

\section{Results and discussion}

For deglet nour, Piarom, Suffry, Safawi, Mabroom and Aliya, the evolution of CO started at $220{ }^{\circ} \mathrm{C}$, $228^{\circ} \mathrm{C}, 219^{\circ} \mathrm{C}, 223^{\circ} \mathrm{C}, 216^{\circ} \mathrm{C}$ and $220{ }^{\circ} \mathrm{C}$ reached its maximum at $520{ }^{\circ} \mathrm{C}, 540{ }^{\circ} \mathrm{C}, 433{ }^{\circ} \mathrm{C}, 526{ }^{\circ} \mathrm{C}$, $500{ }^{\circ} \mathrm{C}$ and $543{ }^{\circ} \mathrm{C}$, respectively; and then declined in a fluctuating manner (Fig. 1). This trend of CO can be explained by the breaking of $\mathrm{C}-\mathrm{C}$ and $\mathrm{C}-\mathrm{O}$ bonds at a temperature of 240 up to $400{ }^{\circ} \mathrm{C}$ [10]. Breaking of bonds is attributed to the presence of hemi-cellulose and cellulose and the evolution of CO at higher temperatures due to lignin.. On the other hand, the evolution of $\mathrm{H}_{2}$ shows two peaks at $470{ }^{\circ} \mathrm{C}$ and $888^{\circ} \mathrm{C}, 479{ }^{\circ} \mathrm{C}$ and $849^{\circ} \mathrm{C}, 480{ }^{\circ} \mathrm{C}$ and $890^{\circ} \mathrm{C}, 479{ }^{\circ} \mathrm{C}$ and $874{ }^{\circ} \mathrm{C}, 483{ }^{\circ} \mathrm{C}$ and $870^{\circ} \mathrm{C}$, and $501{ }^{\circ} \mathrm{C}$ and 844 for Deglet nour, Piarom, Suffry, Safawi, Mabroom and Aliya, respectively. The release of $\mathrm{H}_{2}$ at the lower temperature was caused by the primary pyrolysis[10], while the release of $\mathrm{H}_{2}$ at the higher temperature resulted from the cracking of heavy hydrocarbons. It was established that the prevailing hydrocarbon species in DPSs were $\mathrm{CO}$ and $\mathrm{CH}_{4}$. Moreover, the mole fraction of $\mathrm{CO}$ was 2 to 4 times higher than the mole fraction of $\mathrm{CO}_{2}$.

The kinetic parameters of the evolved species were obtained by applying the techniques described in the previous equations (1-8). For this purpose, the curve of $d m i / d t$ vs. temperature was plotted for the heating rate $\left(20^{\circ} \mathrm{C} / \mathrm{min}\right)$ using the following equation:

$$
\frac{d m i}{d t}=[M F]_{i}(t) \times \rho A r \times \frac{M W_{i}}{M W_{A r}} \times V_{A r}\left(\frac{1}{M I N}\right)
$$



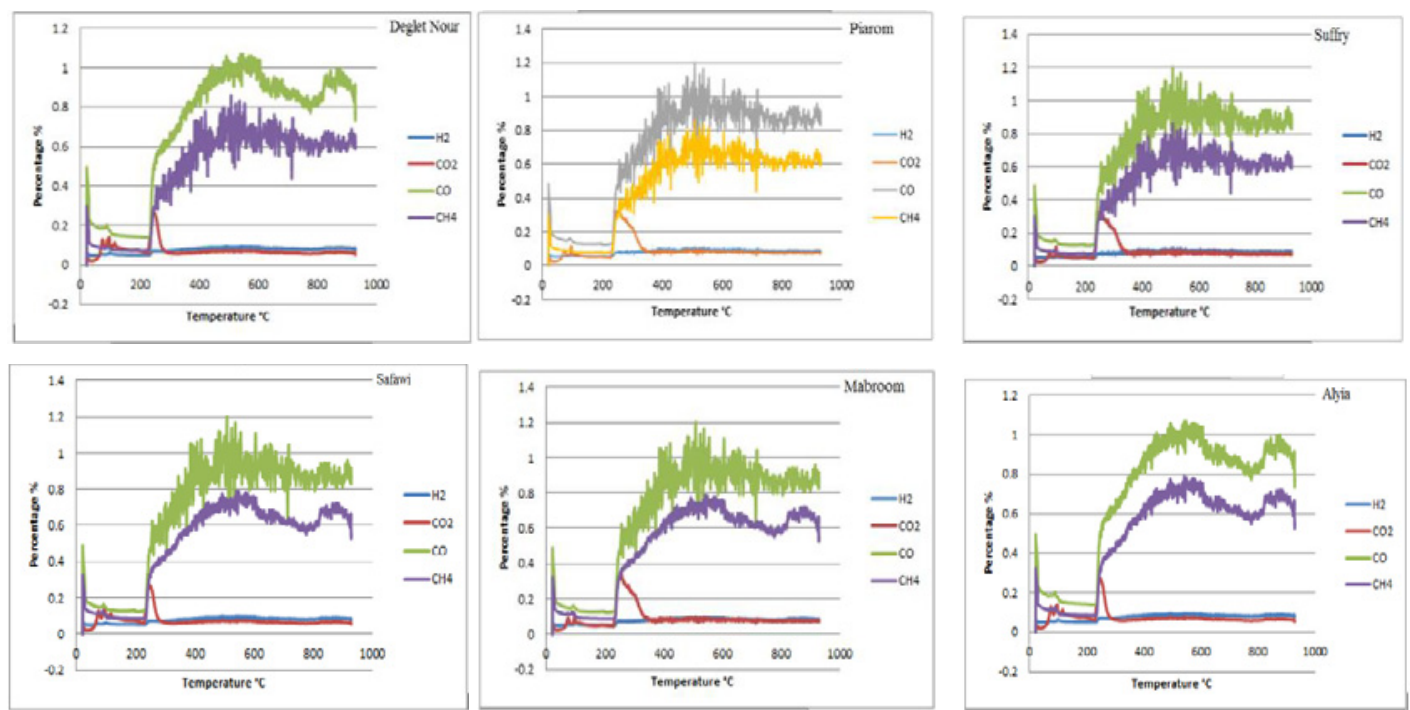

Figure. 1 The evolved gases from DPSs pyrolysis at the heating rate of $20{ }^{\circ} \mathrm{C} / \mathrm{min}$.

Where $[\mathrm{MF}]_{i}(t)$ is the mole fraction of gases $i$ at a time $t, A r$ is argon. $M W_{i}$ is the molecular weight of species $V_{A r}, \rho \mathrm{Ar}$ and $\mathrm{MW}$ Ar are the flow rate (constant), density, and molecular weight of Ar, respectively.
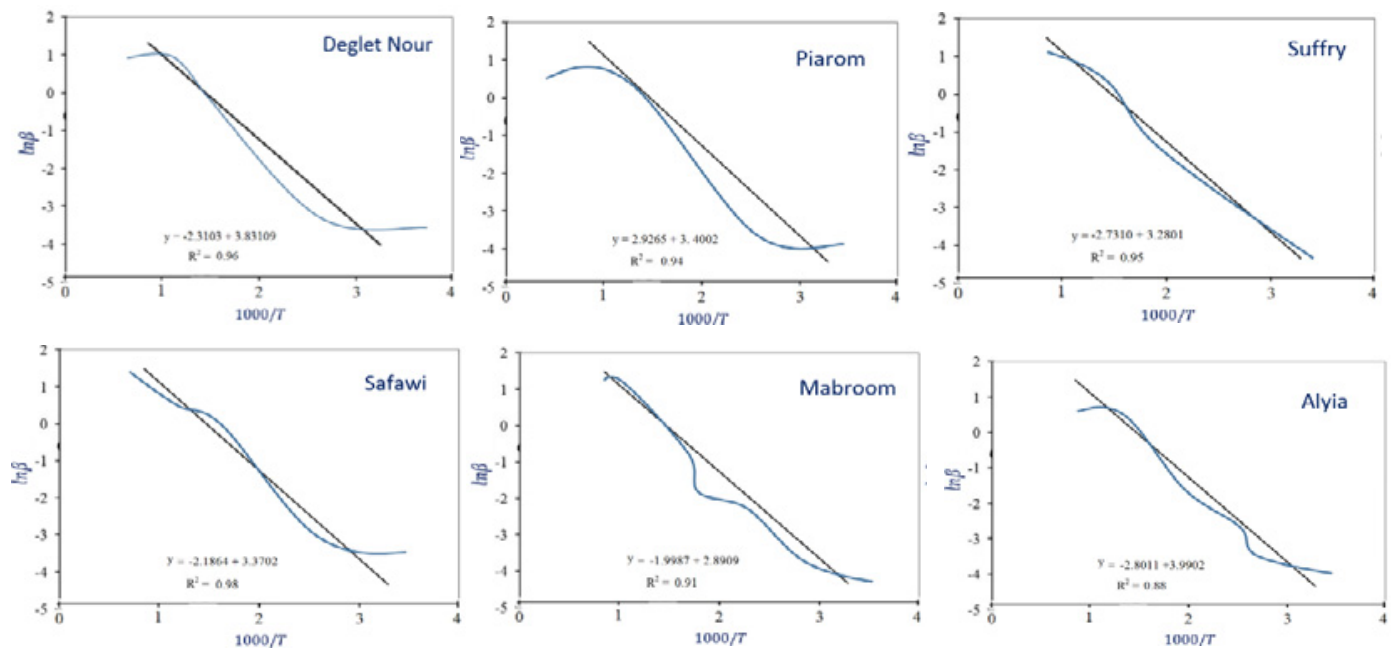

Figure 2 Kinetic plots for DPSs cultivars at $20^{\circ} \mathrm{C} / \mathrm{min}$.

By utilizing the mole fraction data of $\mathrm{CO}, \mathrm{CO}_{2}, \mathrm{H}_{2}$ and THC and the definition of $\beta=d T / d t$, the curves of $d m i / d T$ vs. temperature can be plotted as shown in Fig. 2, where the peak temperatures satisfying the condition of $d^{2} m i / d T^{2} \mid T=T^{2}=0$ for evolved species.

By obtaining the plot of $\ln \left[\beta / \mathrm{T}_{\text {peak }}{ }^{2}\right]$ vs. $1 / \mathrm{T}_{\text {peak }}$ for every pyrolyzed gases in Fig. 3 and applying Eq. 8 to the data of Fig.2, the first-order kinetic parameters (Ai, Ei) were determined (Table 1). 
Table 1 kinetic parameters of the DPSs species.

\begin{tabular}{|c|c|c|c|c|c|}
\hline $\begin{array}{l}\text { DPSs } \\
\text { cultivars }\end{array}$ & Pyrolytic species & $\mathrm{H} 2$ & $\mathrm{CO}$ & $\mathrm{CO} 2$ & $\mathrm{CH} 4$ \\
\hline \multirow[t]{2}{*}{ Deglet Nour } & $\mathrm{E}(\mathrm{kJ} / \mathrm{mol})$ & 44.49 & 53.12 & 58.21 & 48.61 \\
\hline & $\mathrm{A}(1 / \mathrm{min})$ & $2.46 \mathrm{E}+10$ & $2.11 \mathrm{E}+14$ & $9.33 \mathrm{E}+05$ & $3.65 \mathrm{E}+11$ \\
\hline \multirow[t]{2}{*}{ Piarom } & $\mathrm{E}(\mathrm{kJ} / \mathrm{mol})$ & 59.91 & 47.22 & 38.13 & 58.17 \\
\hline & $\mathrm{A}(1 / \mathrm{min})$ & $3.13 \mathrm{E}+11$ & $7.44 \mathrm{E}+07$ & $8.13 E+09$ & $1.67 \mathrm{E}+12$ \\
\hline \multirow[t]{2}{*}{ Suffry } & $\mathrm{E}(\mathrm{kJ} / \mathrm{mol})$ & 61.40 & 49.161 & 60.11 & 43.17 \\
\hline & $\mathrm{A}(1 / \mathrm{min})$ & $6.10 \mathrm{E}+08$ & $4.61 \mathrm{E}+11$ & $2.89 \mathrm{E}+10$ & $9.55 \mathbf{E}+05$ \\
\hline \multirow[t]{2}{*}{ Safawi } & $\mathrm{E}(\mathrm{kJ} / \mathrm{mol})$ & 55.41 & 43.70 & 58.25 & 60.11 \\
\hline & $\mathrm{A}(1 / \mathrm{min})$ & $3.51 \mathrm{E}+11$ & $8.36 \mathrm{E}+07$ & $2.14 \mathrm{E}+15$ & $3.773 \mathrm{E}+08$ \\
\hline \multirow[t]{2}{*}{ Mabroom } & $\mathrm{E}(\mathrm{kJ} / \mathrm{mol})$ & 63.21 & 74.32 & 51.66 & 53.14 \\
\hline & $\mathrm{A}(1 / \mathrm{min})$ & $6.55 \mathrm{E}+01$ & $8.54 \mathrm{E}+07$ & $2.31 \mathrm{E}+06$ & $3.61 \mathrm{E}+12$ \\
\hline \multirow[t]{2}{*}{ Alyia } & $\mathrm{E}(\mathrm{kJ} / \mathrm{mol})$ & 44.46 & 60.16 & 55.31 & 45.12 \\
\hline & $\mathrm{A}(1 / \mathrm{min})$ & $5.23 \mathrm{E}+12$ & $2.31 \mathrm{E}+09$ & $4.14 \mathrm{E}+10$ & $8.12 \mathrm{E}+15$ \\
\hline
\end{tabular}

\section{Conclusion}

TGA and GA were used to measure the effect of using single heating rate on the behavior of evolved gases under non-isothermal condition. To achieve this objective, parallel model technique was used to obtain the pyrolytic parameters. There are four conclusions to be drawn from the findings and discussions:

1. There are three different types of pyrolysis zones depending on the main constituents of every cultivars. These zones have the potentiality to control the overall process of evolved species and the amount of released gases during the pyrolysis.

2. The dominant hydrocarbon species in DPSs evolved species were $\mathrm{CO}$ and $\mathrm{CH} 4$ (40 to $50 \%$ higher than the rest of species). The mole fraction of $\mathrm{CO}$ was 2 to 4 times higher than the mole fraction of $\mathrm{CO} 2$.

3. The activation energy and frequency factor of DPSs evolved species showed that Mabroom has the highest activation energy regarding $\mathrm{H} 2(63.21 \mathrm{~kJ} / \mathrm{mol})$ and $\mathrm{CO}(74.32 \mathrm{~kJ} / \mathrm{mol})$.

\section{References}

[1] J. S. Lim, Z. Abdul Manan, S. R. Wan Alwi, and H. Hashim, Renew. Sustain. Energy Rev., vol. 16, no. 5, pp. 3084-3094, Jun. (2012).

[2] M. A. A. Mohammed, A. Salmiaton, W. A. K. G. Wan Azlina, M. S. Mohammad Amran, A. Fakhru'l-Razi, and Y. H. Taufiq-Yap, Renew. Sustain. Energy Rev., vol. 15, no. 2, pp. 12581270, Feb. (2011).

[3] L. Chen, L. Xing, and L. Han, Renew. Sustain. Energy Rev., vol. 13, no. 9, pp. 2689-2695, Dec. (2009).

[4] T. Abu Hamed, H. Flamm, and M. Azraq, Renew. Sustain. Energy Rev., vol. 16, no. 1, pp. 10821088, Jan. (2012).

[5] R. M. Frings, I. R. Hunter, and K. L. MacKie, Biomass Bioenergy, vol. 2, no. 1-6, pp. 263-278, (1992).

[6] M. Balat, M. Balat, E. Kırtay, and H. Balat, Energy Convers. Manag., vol. 50, no. 12, pp. 31473157, Dec. (2009).

[7] N. Sonoyama and J. Hayashi, Fuel, vol. 114, pp. 206-215, Dec. (2013).

[8] A. K. Sadhukhan, P. Gupta, T. Goyal, and R. K. Saha, Bioresour. Technol., vol. 99, no. 17, pp. 8022-8026, Nov. (2008).

[9] K. Hashimoto, I. Hasegawa, J. Hayashi, and K. Mae, Fuel, vol. 90, no. 1, pp. 104-112, Jan. (2011).

[10] J. E. White, W. J. Catallo, and B. L. Legendre, J. Anal. Appl. Pyrolysis, vol. 91, no. 1, pp. 1-33, May (2011).

[11] B. L. F. Chin, S. Yusup, A. Al Shoaibi, P. Kannan, C. Srinivasakannan, and S. A. Sulaiman, Journal of Cleaner Production, vol. 70, pp. 303-314, May. (2014). 